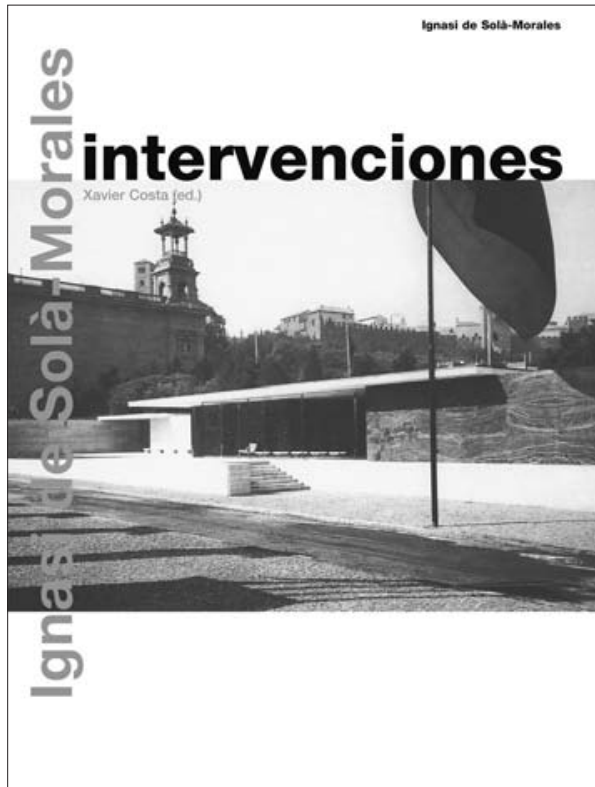

Conversaciones con Mies van der Rohe. CERTEZAS AMERICANAS

Moisés Puente, editor

Editorial Gustavo Gili S.A., Barcelona

96 páginas, $14,5 \times 20 \mathrm{~cm}$, duetono

2006

Texto castellano

Web www.ggili.com

Tres conversaciones con Mies entre 1950 y 1961, certeras y precisas, por ejemplo: "la altura interior, por lo general, es de 2.54 m"; la importancia tajante del profesional arquitecto: "dijimos que deberían aceptarlo tal y como estaba o, de lo contrario, no lo construíamos". (Lafayette Park 1955-1963) 0 la franqueza "esas estúpidas casas suburbanas". La actitud ante el proyecto mismo es sin embargo humilde: "ha sido el resultado de un desarrollo lento"... "las respuestas aparecieron gradualmente". Pero también: "siempre presentamos un solo proyecto, el cliente no tiene que escoger ¿cómo podría hacerlo".

Un libro para entusiastas y detractores de Mies, indispensable para ambos.

\section{$<$ INTERVENCIONES}

Ignasi de Solà-Morales

Editorial Gustavo Gili S.A., Barcelona

160 páginas, $18 \times 21,8 \mathrm{~cm}, \mathrm{~b} / \mathrm{n}$

2006

Texto castellano

Web www.ggili.com

"Intervención" o "interpretación" es una palabra que usa el autor, alejándose de la ortodoxia de "restaurar", esta con un significado original y unívoco, que separa al edificio de la realidad circundante y de alguna manera lo embalsama. Las restauraciones tienen una fecha que es la del tiempo en que se hacen, y eso es inevitable y más vale trabajar con ello.

Varios textos de Solà-Morales discuten con finura y profundidad su propia actuación en obras como el Pabellón Mies van der Rohe o el Teatro Liceu, ambos en Barcelona. Especialmente actual es el del montaje de la exposición de 1982, en que se enfrenta a la tarea de tratar con el mayor artista antifetichista del s. XX, Marcel Duchamp.Un libro muy recomendable para arquitectos, restauradores o no.

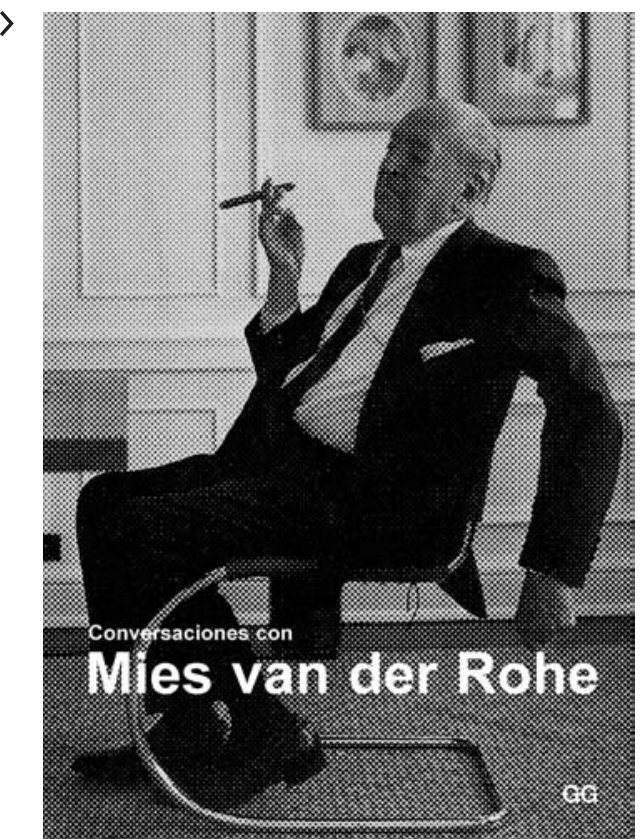

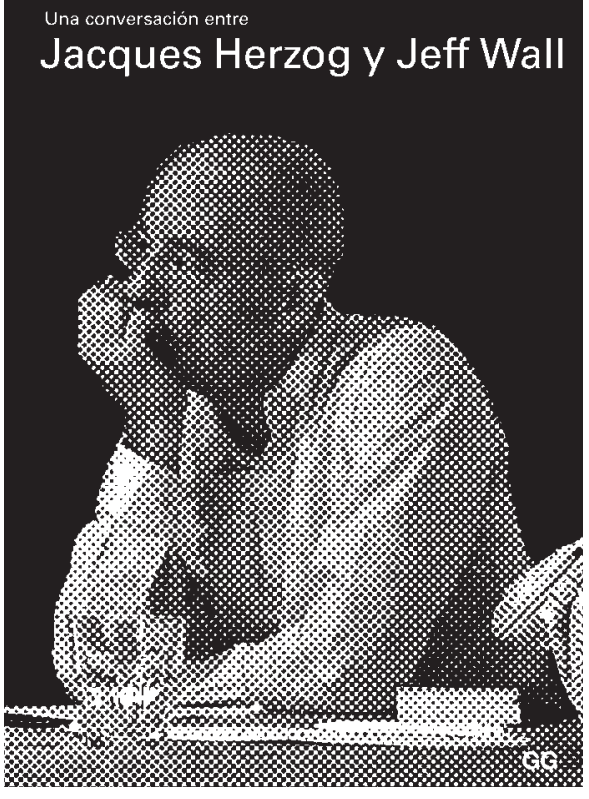

Una conversación entre Jacques Herzog Y JefF WALL

\section{Philip Ursprung, editor}

Editorial Gustavo Gili S.A., Barcelona

80 páginas, $14 \times 20 \mathrm{~cm}$, color

2006

Texto castellano

Web www.ggili.com

Jacques Herzog y el fotógrafo Jeff Wall intercambian ideas sobre los procesos de sus respectivos trabajos: arquitectura y fotografía, disciplinas que resultan esclarecedoras y complementarias. La decisión de pensar por cuenta propia fue para ambos y especialmente para Herzog \& de Meuron lo que les impidió caer en esos episodios efímeros y consecutivos que se llamaron "postmodern" y "decontructivismo". Un libro de bolsillo cuidadosamente editado que nos debiera acompañar para no caer en las tentaciones de moda que se reiteran y que se acercan a las antiguas bobadas, efímeras que dejan en pie edificios durante 50 años.

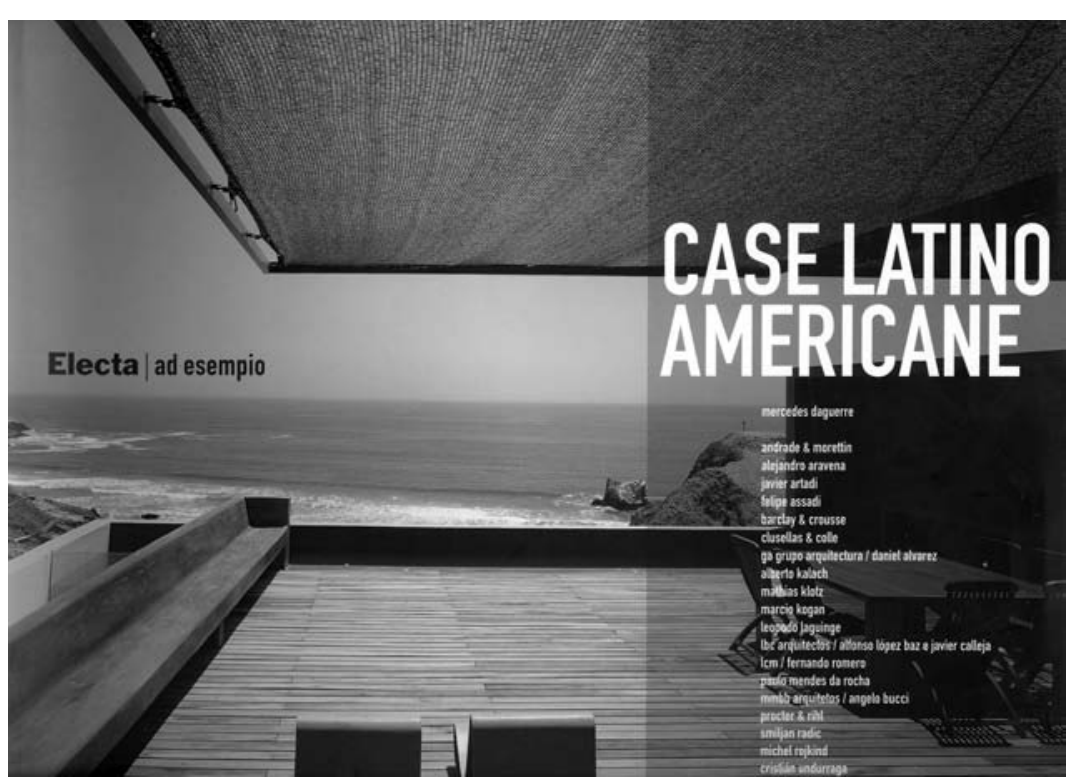

$<$ Case Latinoamericane

Mercedes Daguerre

Editorial Mondadori Electa S.p.A., Milán

240 páginas, $30,5 \times 25 \mathrm{~cm}$, color

2006

Texto italiano

Web www.electaweb.com

El libro recoge una buena selección de casas de México al sur, de veinte arquitectos latinoamericanos entre los cuales una cuarta parte, cinco, son chilenos.

Si bien no se puede extraer más que la anterior conclusión de tipo estadístico que favorece a Chile, hay en la mayoría de ellas oficio y un cierto aire que podría ser parecido a un aire de familia, y que también responde a una clase media alta, o derechamente alta, con medio económicos, viajes y un espesor cultural propio, o del diseñador, y arquitecto recomendados al cliente que quiere estar "a la page". Una bien cuidada edición en italiano de la cual se hecha de menos que no haya una traducción al castellano, del prólogo de Mercedes Daguerre. 